\title{
Determinants of Sustainability in Recycling of Municipal Solid Waste: Application of Community-Based Social Marketing (CBSM)
}

\author{
Esmat Heydari ${ }^{1}$, Mahnaz Solhi $^{1, *}$, Leila Janani ${ }^{2}$ and Mahdi Farzadkia ${ }^{1}$ \\ ${ }^{1}$ Department of Health Education and Health Promotion, Faculty of Public Health, Iran University of Medical \\ Sciences, Tehran, Iran \\ 2 Department of Biostatistics, School of Public Health, Iran University of Medical Sciences, Tehran, Iran \\ * Corresponding author: solhi.m@iums.ac.ir; Tel.: +98 2186704756
}

Submitted: 7 July 2020 | In revised form: 1 February 2021 | Accepted: 9 March 2021 |

Published: 26 May 2021

\begin{abstract}
Waste management and promotion of source separation by the public requires identification of the determinants of waste separation behavior, raising awareness, and reinforcing such behaviors. The present study aimed to determine the status of source separation behavior and identify the barriers, benefits, and factors affecting this behavior in Iran. This is a descriptive-analytic cross-sectional study conducted on 300 women selected through stratified sampling. The questionnaire applied included three sections. The validity and reliability of the self-made questionnaire were confirmed. In this study, descriptive statistics including the percentage, frequency, mean and standard deviation were used to describe the data, while chi-square and Fisher exact tests were applied to analyze the data. Logistic regression test was also used to determine the predictors of waste separation behavior. Only $17.7 \%$ of the respondents separated the wastes regularly. The age, level of education, benefits $(\mathrm{OR}=6.746 ; 95 \% \mathrm{Cl}=2.534-17.959)$, structural barriers $(\mathrm{OR}=12.734 ; 95 \% \mathrm{Cl}=3.516-46.119)$, motivation ( $\mathrm{OR}=9.613 ; 95 \% \mathrm{Cl}=3.356-27.536)$, awareness $(\mathrm{OR}=3.917 ; 95 \% \mathrm{Cl}=3.351-11.356)$, and social norms $(\mathrm{OR}=2.905 ; 95 \% \mathrm{Cl}=1.030-8.191)$ were the determinants of source separation behavior. Considering the low participation rate in waste separation, efforts required to enhance such behavior need proper policy-making, training programs, and infrastructure to encourage the individuals to participate actively in waste separation. Educational interventions and campaigns are recommended to be designed to raise awareness and empower people.
\end{abstract}

Keywords: community-based social marketing; municipal solid waste; recycling; source separation

\section{Introduction}

One of the major environmental concerns across the world is the high waste production, especially in developing communities [1]. Based on the reports and statistics from developed countries, 1-8 kg solid waste is produced per household in each day which results in having more than 5 million tons of municipal and industrial solid waste annually [2]. Given that every Iranian citizen generates an average of 700 to 1000 grams of solid waste per day, food waste, dry recyclable waste and hazardous waste approximately account for $70 \%, 29 \%$ and $1 \%$ of the contents of the solid wastes, respectively [3]. 
The increase in solid waste production and its disposal to the environment without proper recycling can jeopardize the ecosystem as well as the public health. Lack of separation of the household wastes from chemical and hazardous wastes could have devastating effects on the environment of large cities [4]. Due to the increased production of wastes and ultimately the costs of their collection and disposal, managing these wastes has become a serious challenge [5]. Therefore, establishing a systematic waste collection and disposal system to properly deal with the waste dumping problem and lack of collection and disposal of waste is a crucial need [2].

In the waste management plan, two important solutions to improve the waste management system are source separating and recycling [6]. Recycling is one of the most effective methods of municipal waste management; it is worth mentioning that the depletion of natural resources and environmental degradation are the result of neglecting recycling [7]. Based on the results of previous studies, currently less than $10 \%$ of municipal waste is recycled in developing countries, and only a small number of these recyclables meet acceptable standards [8-10]. Countries such as US and Switzerland recycle $50-80 \%$ of their wastes, while this is less than $10 \%$ in Iran [11].

The first recycling step is source separation which is an important method in having a scientific waste management process. This is mainly due to the proper sorting and separating of the waste which lead to more efficient refinement and disposal [12-14]. Source separation is also helpful in reducing the amount of waste which ends up at landfill [15]. The source separation method can be applied to fulfill different goals, including recycling a major part of the municipal waste and returning it to the cycle of production and reuse, dramatically reducing the volume and weight of municipal waste, reducing the costs of waste collection and disposal, boosting the economy through reusing the reusable waste materials, saving the land required for landfill and reducing the related costs, and reducing depreciation and maintenance costs for compost factories and producing high quality compost [12-14]. In case source separation is not considered, dry waste can be mixed with corrosive waste, reducing the quality of recyclables and causing skin diseases, typhoid fever, cholera, and infectious diarrhea [16]. According to the Waste Management Act in Iran, waste collection should be done separately from the source in cities with over one million residents by the end of 2011 and in other cities by the end of 2014. Source separation in Iran is of high importance since waste components and compounds can be recycled up to $70 \%$ or more. Furthermore, approximately $20 \%$ of the waste in Iran consists of paper, cardboard, plastic, glass, and recyclable materials [17].

The role and participation of citizens are important in the field of recycling and source separation since the citizens are the owners of the city and have a decisive role in improving the hygiene and health of the urban environment and implementing the plans and programs. In addition, active participation of the citizens requires sufficient knowledge and awareness and a positive attitude toward this issue $[13,18]$. By training and engaging people in source separation, most advanced countries, namely Germany [19] and Sweden [20], began their activities in this regard. In Turkey, the results of a study indicated that approximately $80 \%$ of the population was willing to participate in the recycling program [21]. Various factors affect the source separation behavior [15]. The previous studies reported that the amount of knowledge and use of information sources, marital status and income were effective in the emergence of source separation behavior [22,23]. Also, awareness and motivation of individuals were also important factors in the source separation behavior [15,24,25].

\section{Approach Framework}

An effective approach that tries to promote and improve desirable behavior by identifying barriers and benefits of people's behavior and using marketing techniques is communitybased social marketing (CBSM). CBSM is an effective behavior change approach that combines community-based participatory research with the methods and principles of social marketing. We first identified the benefits and barriers that hinder or encourage sustainable behaviors, and then developed strategies to reduce the identified barriers and increase benefits. The CBSM process consists of 5 steps: 1. selecting behavior, 2 . identifying barriers and benefits, 3 . developing strategies, 4 . piloting the program (implementing interventions), and 5.implementing the program. CBSM uses 7 tools to perform the interventions [26].

\subsection{Literature Review}

Various studies based on CBSM have been conducted specifically for sustainable behaviors such as municipal solid waste, waste reduction, food recycling and composting, paper recycling in educational and academic centers, and energy efficiency [27-32].

CBSM is a research-based approach that includes 5 steps. The first two steps include choosing a behavior and identifying the barriers and benefits of the behavior that are very important. In the next three steps, strategies should be designed and implemented based on the identified obstacles and benefits. However, CBSM studies have not adequately investigated on the first two steps and have more focused on choosing strategies and implementing interventions. However, the first two steps are the foundation of the work and until the barriers and benefits of the behavior are well defined from the perspective of the audience, it is not possible to design the desired interventions [26]. Accordingly, in this study, based on steps one and two of CBSM, we tried to identify the barriers and benefits of separation of waste from the source from the perspective of individuals, so that in the next steps we can design effective interventions.

In addition, to identify the barriers and benefits of source separation of waste, we reviewed the literature, and these barriers and benefits are displayed in Table 1 [33,34,34-44]. 
Table 1. Barriers and benefits identified based on literature review.

\begin{tabular}{ll}
\hline Barrier & Benefit \\
\hline - Situational barriers (lack of sufficient bins, insufficient storage space, & - Protecting the environment \\
lack of access to recycling sites) & \\
- Behavioral barriers (lack of space at home to recycle, being too & - Preserving the landfill space \\
busy, forgetting to dispose of the waste) & - creating inner satisfaction, \\
- Lack of sufficient knowledge and awareness & - reducing waste generation at home \\
- Attitudinal and perceptual barriers & - protecting THE resources for future generations \\
- The cost to be paid for subscribing to the recycling program & - Helping to create a cleaner city \\
- Lack of ease in recycling & - Helping to make potential financial gains \\
- Lack of enough time to recycle & - Helping to increase civil liability Creating jobs in local communities \\
- Insufficient materials for recycling & \\
- Need to a lot of activity and effort for recycling & \\
- Distance from waste collection centers & \\
- Lack of rewards & \\
- Lack of participation of family members or relatives & \\
- Lack of interest & \\
- Insufficient commitment & \\
- Lack of executive requirements & \\
- Unfamiliarity with the recycling routines &
\end{tabular}

\subsection{Objectives}

Given the significance of municipal solid waste source separation behavior in the field of waste management, investigating the status of this behavior and its influential factors can play an effective role in enhancing municipal solid waste management. Regarding the significance of this issue, the present study aims at investigating the present status of municipal solid waste source separation behavior and identifying the barriers, benefits and factors affecting this behavior which can be useful in enhancing and reinforcing such behavior in Iran.

\subsection{Solid Waste Management System in Genaveh}

Genaveh port has a population of 90189 in 15752 families. The area of this city is about 1837 square kilometers and is located in the north coast of the Persian Gulf. According to the Law on Waste Management in Iran, municipalities are responsible for all municipal waste except industrial and special wastes. In addition, the municipality is responsible for separating the waste from the source for recycling. By making a contract with the private sector, the Municipal Waste Management Organization (NWMO) in the port city of Genaveh, has delegated this task to the private sector. However, the private sector is content only with the separation of solid waste (cardboard and paper) from the commercial sectors of this port city, and currently there is no coherent plan for the separation of municipal solid waste from doorsteps.
At present, households usually collect all their waste in a garbage bag and put it in special waste bins on the street every day. Municipal waste trucks transport these collected waste to the landfill outside the city on a daily basis by attending the streets and alleys. Genaveh landfill is located in a land area of about two square kilometers located 15 kilometers north of Genaveh.

Of course, among households, people separate and sell valuable materials such as paper, cardboard, plastic and metals because of their interest in the environment or because of the economic importance of dry waste. Also, a private company at the landfill separates the dry waste from wet one as much as possible, which is a very difficult task.

In the interviews conducted during this study with the private sector and the Municipal Waste Management Organization of Genaveh Port, several reasons for the failure of the municipal solid waste separation program from the source have been mentioned: a) Most households' desireto sell valuable dry waste (such as cardboard, metals, plastics, etc.); b) Existence of tourists in the city who purchase the dry waste from households; and c) The short duration of contracts that the municipality makes with the private sector and on the other hand the need to long-term education and culture for the separation of waste from the source, which is not cost-effective for the private sector due to the short duration of contracts and ... cited. In fact, because the source separation of municipal solid waste is one of the problems in the health sector in Ganaveh, we decided to study it. 


\section{Methodology}

\subsection{Calculation of Climate Variability}

This is a cross-sectional descriptive-analytical study conducted on women in Genaveh, Bushehr province, Iran in 2019 , as a part of a larger study on designing, implementing, and evaluating a community-based social marketing model on municipal solid waste source separation. In order to identify the barriers and benefits of source separation in this work, we performed a comprehensive literature review and a qualitative study on this issue.

The literature review aimed at identifying the barriers and benefits of source separation using relevant Persian and English keywords. The author divided the selected studies into two categories, including studies on waste separation barriers and those on waste separation benefits. The concepts and themes related to the barriers and benefits of source separation were extracted through the reviewed studies which were applied for conducting the qualitative study.

Since municipal solid waste separation in each community depends on various cultural, social, economic and infrastructure factors of that community, a focus group discussion was conducted to identify the barriers and benefits of source separation. Purposive sampling with maximum variability was used in this study. In order to obtain more accurate and complete information, citizens with different demographic characteristics, i.e. people of different ages, levels of education, and different places of residence, different jobs and specialties were used. Citizens were invited to participate in group discussions through health centers. Thus, after attending the centers, according to the family list of the health center, a number of women in the family were randomly contacted. We asked questions about the separation or non-separation of waste after explaining the purpose of the study, the participants were asked to participate in group discussion sessions if they wished. After the initial telephone conversation, the subjects were divided into two groups: 1 - Those who performed waste separation and 2- those who didn't. Some of them were randomly contacted and invited to participate in the discussion. Three sessions of focus group discussion were held for each group (6 sessions in total for both groups) with 8 individuals attending each session, until we reached the data saturation, so that no new items were presented by the participating women. Written consent was obtained from the participants in group discussions and ethical considerations were taken into account.

In order to prepare the study questionnaire, only the findings of the group discussion in this study were used. The reason why the texts were reviewed before the group discussion was because the researcher was sufficiently aware of the barriers and benefits from the point of view of different people to be able to challenge the participants in the group discussion sessions.

The participants in group discussion sessions usually presented only a few of the barriers and benefits, but the researcher asked the participants to mention whether the extracted barriers and interests were among their perceived barriers and benefits. And through data saturation achieved. Questionnaire items were compiled based on the highest frequency reported by the participants.

We conducted a pilot study with 50 people to determine the sample size at $95 \%$ confidence level and $80 \%$ power to determine a $50 \%$ difference in the response rate between the two groups. With the $0.12 \%$ rate to in-group under 30 years and $25 \%$ in the group over 30 years, we calculated the sample size 278 subjects. For more accuracy, a sample size of 300 people was considered.

The participants in this study were the women residing in Genaveh, Bushehr Province, Iran. As to a sufficient sample size for this study, six participants were considered for each variable (i.e. 48 variables). Given the probable attrition, 300 participants were selected as the sample size to allow accurate estimation of the consequences. The probability stratified sampling method proportional to the size was used. The strata in this study were the health centers located in Genaveh. The participants were selected form these 6 health centers and sampled according to the frequency of households.

Using Integrated Health System database, we selected the participants based on random sampling method and their relevant data was entered to SPSS software for further analysis. Then, the selected participants were contacted and asked to fill the questionnaires. The inclusion criteria were 1) being a resident of Genaveh City, 2) being literate so that they can read and answer questions, 3) being willing to participate in the study, and 4) signing a written informed consent. Also, the exclusion criterion was unwillingness to participate in the study.

The data collection instrument was a questionnaire designed in three sections. The first section contained questions on demographic characteristics (e. g. age, marital status, academic level, etc.) of the population under the study. The second section was related to municipal solid waste separation behavior and was answered by the subjects through a yes/no question, and 6 multiple-choice questions on how to perform waste separation. The third section was a selfmade questionnaire. The literature review indicated that there was no instrument for measuring the barriers and benefits of waste separation, so the questionnaire applied in this work was designed based on the population selected in this work; in other words, the separation behavior is affected by social, cultural and structural factors of a local society.

The self-made questionnaire had 48 items. In order to validate the questionnaire, we assessed and confirmed the content, face and structural validity and reliability of the questionnaire. To conduct a qualitative content validity, we asked 12 health education and environmental health professors and professionals to evaluate the questionnaire in terms of appropriate words, right placement of items, grammar compliance and appropriate scoring and feedback [41]. Because the professors of health education and health promotion have sufficient expertise and knowledge in the field 
of instrument making and also the issue of waste separation from the source is a topic that is in the field of expertise of environmental health professors, these specialties were used to validate the tool.

For the quantitative content validity, the comments of the experts were collected to determine the content validity ratio (CVR) as to the need or necessity of each item. Questions with a score above 0.56 were included in the questionnaire and 6 questions with a score below 0.56 were removed from the questionnaire [42]. Content validity index (CVI) was also assessed for relevance, clarity and simplicity of each item. Based on the results, all questions were scored above 0.79 , except for one question that was revised [43].

To determine the qualitative face validity, we presented the items to 10 women and the difficulty of understanding the items and words, their ambiguity and misunderstanding of the items and their semantic defects were investigated and corrected. In the quantitative section, relying on the Impact score method, inadequate items (scores below 1.5) were eliminated and the significance of each item was determined [41]; also, to evaluate the construct validity, the SPSS and R software were used. Based on the results, the 5 and 7 factor models had an appropriate fitness after exploratory factor analysis. Given the possibility of the existence of some items in several factors, and according to McKenzie-Mohr's proposed structure for classifying the barriers and benefits of sustainable behavior in community-based social marketing, and also the research team's view, the questionnaire items were categorized into five barrier factors and a waste separation benefit factor. It should be noted that a confirmatory factor analysis was also performed. A single confirmatory factor analysis was first performed for each construct, and items that did not fit the construct were identified. Having consulted with the expert team, we removed the items incompatible with the provided structures or moved them across the factors. All loadings were significant. The Root Mean Square Error of Approximation (RMSEA) value in this study was 0.052 and the Chi-square/df index in the present study was 2.23. Based on the analysis of the reliability questionnaire, the intra-class correlation coefficient was 0.83 . Using Cronbach's alpha coefficient, we calculated the internal consistency results of the questions, which was 0.92 . After validation, the final questionnaire consisted of 5 constructs, namely waste separation benefits ( 9 items), structural barriers (14 items), motivation (21 items), awareness ( 2 items), and social norms ( 2 items), which were designed in a 5-point Likert scale ranging from strongly agree (1 point) to strongly disagree (5 points).

The approval of the Ethics Committee of Iran University of Medical Sciences was obtained to conduct this study. After collecting and coding the data, they were analyzed by SPSS software V. 22. Mean and frequency were used to describe the data, and chi-square and Fisher tests at the significance level of $<0.05$ were used to assess the correlation between context variables, barriers and benefits with waste separation behavior. To determine the predictors of waste separation behavior, we also used the logistic regression. We examined goodness-of-fit of the model using Hosmer-Lemeshow test ( $p>0 / 05)$.

\section{Results}

Among the 300 women participating in the study, 218 $(72.7 \%)$ and $82(27.3 \%)$ were married and single, respectively. The participants' minimum age was 16 and the maximum was 54 years with a mean (SD) of 29.83 (7.30). Among the participants, 94 (31.3\%) had two children and $107(35.7 \%)$ had 5 or more family members; of them, $175(58.4 \%)$ participants had university education. The house of $229(76.3 \%)$ respondents was large with a yard. As to the employment status, 186 subjects (62\%) were housewives (Table 2).

In the constructs of benefits, a score of minimum 14 and maximum 33 with a mean (SD) of 21.09 (3.93) was obtained. The minimum and maximum scores of structural barriers were 14 and 70, respectively, with a mean (SD) of 43.89 (10.48). The motivation construct was scored a minimum of 27 and a maximum of 105 with a mean (SD) of 70.06 (16.09).

Table 2. Analysis of annual rainfall variability for 1981 to 2018.

\begin{tabular}{|c|c|c|c|}
\hline \multicolumn{2}{|c|}{ Variables } & \multirow{2}{*}{$\begin{array}{r}\text { Number } \\
218\end{array}$} & \multirow{2}{*}{$\begin{array}{r}\text { Percentage } \\
72.7\end{array}$} \\
\hline Marital status & Married & & \\
\hline Miantal status & Single & 82 & 27.3 \\
\hline \multirow{4}{*}{ Number of the children } & No children & 99 & 33 \\
\hline & 1 child & 59 & 19.7 \\
\hline & 2 children & 94 & 31.3 \\
\hline & $\begin{array}{l}3 \text { children and } \\
\text { more }\end{array}$ & 48 & 16 \\
\hline \multirow{4}{*}{$\begin{array}{l}\text { Number of family } \\
\text { members }\end{array}$} & 2 and less & 26 & 8.7 \\
\hline & 3 & 62 & 20.7 \\
\hline & 4 & 105 & 35 \\
\hline & 5 and more & 107 & 35.7 \\
\hline \multirow{4}{*}{ Academic level } & Elementary & 25 & 8.3 \\
\hline & Middle school & 25 & 8.3 \\
\hline & Diploma & 75 & 25 \\
\hline & Academic & 175 & 58.4 \\
\hline \multirow{4}{*}{ Academic level of wife } & Elementary & 12 & 4 \\
\hline & Middle school & 40 & 13.3 \\
\hline & Diploma & 76 & 25.3 \\
\hline & Academic & 92 & 30.7 \\
\hline \multirow{2}{*}{ Housing type } & With a yard & 229 & 76.3 \\
\hline & Apartment & 71 & 23.7 \\
\hline \multirow{5}{*}{ Employment status } & Housekeeper & 186 & 62 \\
\hline & Employee & 46 & 15.3 \\
\hline & Worker & 1 & 0.3 \\
\hline & University student & 34 & 11.3 \\
\hline & Other Jobs & 33 & 11 \\
\hline \multirow{5}{*}{$\begin{array}{l}\text { Employment status } \\
\text { of wife }\end{array}$} & Employee & 41 & 13.7 \\
\hline & Worker & 10 & 3.3 \\
\hline & Retired & 3 & 1 \\
\hline & University student & 2 & 0.7 \\
\hline & Other Jobs & 164 & 54.7 \\
\hline \multirow[t]{2}{*}{ Age years } & $\begin{array}{l}\text { Minimum- } \\
\text { Maximum }\end{array}$ & Mean & SD \\
\hline & $16-54$ & 29.83 & 7.3 \\
\hline
\end{tabular}


Table 3 indicates the status of the source separation and some of its features among the participants. Based on these results, $53(17.7 \%)$ of the respondents performed waste separation regularly and 247 (82.3\%) of them did not perform waste separation or did not do it regularly Dried bread with a frequency of $53(17.7 \%)$ was the highest amount separated by the participants. 77 participants $(25.7 \%)$ responded that the last time they received information on separation and recycling had been three months ago. The highest waste separation was also made by women (16.7\%) (Table 4).

Table 5 indicates the status of the research variables based on the separating behavior. The chi-square test was used to investigate the relationship between age, marital status, academic level, and academic level of wife, number of children, benefits, structural barriers, motivation, awareness, and social norms. The chi-square test compares two variables in a contingency table to see if they are related. In our study, we used simple random sampling and the variable under the study was categorical (some variable are categorical and we categorized the other variables like age). We aimed to show a relationship between the two variables; that is why we used chi-square.

Fisher test was used to determine the relationship between individual employment status and their wife's employment status since chi-square test was not suitable for this analysis. According to the results of the tests, there was a statistically significant relationship between the age, marital status, academic level, academic level of wife, employment status, number of children, benefits, structural barriers, motivation, awareness and social norms and source separation behavior $(p<0.05)$. However, no statistical relationship was found between the type of house and the employment status of the wife with source separation behavior.
Table 3. Status of the study subjects in terms of independent variables.

\begin{tabular}{lrrrrrr}
\hline Variable & $\begin{array}{c}\text { Mini- } \\
\text { mum }\end{array}$ & $\begin{array}{c}\text { Maxi- } \\
\text { mum }\end{array}$ & Mean & SD & $\begin{array}{r}\text { Lower } \\
\text { limit }\end{array}$ & $\begin{array}{r}\text { Upper } \\
\text { limit }\end{array}$ \\
\hline Benefits & 14 & 33 & 21.09 & 3.93 & 20.64 & 21.54 \\
Structural & 14 & 70 & 43.89 & 10.48 & 42.72 & 45.12 \\
Barriers & & & & & & \\
Motivation & 27 & 105 & 70.06 & 16.09 & 68.30 & 71.87 \\
Awareness & 2 & 10 & 6.87 & 1.90 & 6.66 & 7.07 \\
Social Norms & 2 & 10 & 7.12 & 1.87 & 7 & 7.44 \\
\hline
\end{tabular}

Table 4. The status of the study subjects on waste separation behavior.

\begin{tabular}{llrr}
\hline \multicolumn{2}{c}{ Variable } & Number & Percentage \\
\hline Regular source & Yes & 53 & 17.7 \\
separation behavior & No & 247 & 82.3 \\
\hline & Dried bread & 53 & 17.7 \\
Separated & Plastic & 51 & 17 \\
materials & Glass & 24 & 8 \\
& Metals & 29 & 9.7 \\
& Paper, magazines & 30 & 10 \\
& and cardboard & & \\
\hline Last time they & Three months ago & 77 & 25.7 \\
received separation & Six months ago & 86 & 28.7 \\
and recycling & A year ago & 37 & 12.3 \\
information? & More than a year ago & 60 & 20 \\
& Never & 40 & 13.3 \\
\hline Who does the waste & Women & 50 & 16.7 \\
separation at home? & Men & 11 & 3.7 \\
& Children & 5 & 1.7 \\
\hline
\end{tabular}


Table 5. Results of the relationship between the source separation behavior and the independent variables.

\begin{tabular}{|c|c|c|c|c|}
\hline \multirow{2}{*}{\multicolumn{2}{|c|}{ Variable }} & \multicolumn{2}{|c|}{ Source Separation } & \multirow[t]{2}{*}{ P. value } \\
\hline & & Yes (\%) & No (\%) & \\
\hline \multirow{2}{*}{ Age } & Less than 30 years & $18(11.2)$ & $143(88.8)$ & \multirow{2}{*}{0.001} \\
\hline & Equal and more than 30 years & $35(25.2)$ & $104(74.8)$ & \\
\hline \multirow{2}{*}{ Marital Status } & Married & $45(20.6)$ & $173(79.4)$ & \multirow{2}{*}{0.018} \\
\hline & Single & $8(9.8)$ & 74(90.2) & \\
\hline \multirow{4}{*}{ Academic level } & Elementary & $2(8)$ & 23(92) & \multirow{4}{*}{0.018} \\
\hline & Middle school & $7(8)$ & 23(92) & \\
\hline & Diploma & $6(8)$ & $69(92)$ & \\
\hline & Academic & $43(24.6)$ & $132(75.4)$ & \\
\hline \multirow{4}{*}{$\begin{array}{l}\text { Academic level } \\
\text { of wife }\end{array}$} & Elementary & $4(33.3)$ & $8(66.7)$ & \multirow{4}{*}{0.02} \\
\hline & Middle school & $12(30)$ & $28(70)$ & \\
\hline & Diploma & $11(14.5)$ & $65(85.5)$ & \\
\hline & Academic & $19(20.7)$ & $73(79.3)$ & \\
\hline \multirow{5}{*}{ Employment status } & Home keeper & $45(24.2)$ & $141(75.8)$ & \multirow{5}{*}{0.003} \\
\hline & Employee & $2(4.3)$ & $44(95.7)$ & \\
\hline & Worker & 0 & $1(100)$ & \\
\hline & University student & $3(8.8)$ & $31(91.2)$ & \\
\hline & Other Jobs & $3(9.1)$ & $30(90.9)$ & \\
\hline \multirow{5}{*}{ Employment status of wife } & Employee & $9(8.8)$ & 73(91.3) & \multirow{5}{*}{0.74} \\
\hline & Worker & $4(22)$ & $32(78)$ & \\
\hline & Retired & $1(33.1)$ & $2(66.7)$ & \\
\hline & University student & $1(50)$ & $1(50)$ & \\
\hline & Other Jobs & $31(18.9)$ & $133(81.1)$ & \\
\hline \multirow{2}{*}{$\begin{array}{l}\text { Number of } \\
\text { children }\end{array}$} & No children & $12(12.1)$ & $87(87.9)$ & \multirow{2}{*}{0.05} \\
\hline & One child and more & $41(20.4)$ & $160(79.6)$ & \\
\hline \multirow[t]{2}{*}{ Benefits } & Down & $10(5.5)$ & $172(94.5)$ & \multirow{2}{*}{0.001} \\
\hline & Up & $43(36.4)$ & $75(63.6)$ & \\
\hline \multirow[t]{2}{*}{ Structural barriers } & Down & $49(32.7)$ & $101(67.3)$ & \multirow{2}{*}{0.001} \\
\hline & Up & $4(2.7)$ & $146(97.3)$ & \\
\hline \multirow[t]{2}{*}{ Motivation } & Down & $8(4.4)$ & $175(95.6)$ & \multirow{2}{*}{0.001} \\
\hline & Up & $45(38.5)$ & $72(61.5)$ & \\
\hline \multirow[t]{2}{*}{ Awareness } & Down & $10(5.7)$ & $165(94.3)$ & \multirow{2}{*}{0.001} \\
\hline & Up & $43(34.4)$ & $82(65.6)$ & \\
\hline \multirow[t]{2}{*}{ Social norms } & Down & $13(7.6)$ & $157(92.4)$ & \multirow{2}{*}{0.001} \\
\hline & Up & $40(30.8)$ & $90(69.2)$ & \\
\hline
\end{tabular}

As can be seen in Table 6, the logistic regression test determined the source separation behavior. According to the results for age, the odds ratio of 30-year old individuals and older for source separation behavior was 2.4 times higher than those under 30 years of age $(\mathrm{OR}=2.429 ; 95 \% \mathrm{Cl}=$ 1.143-7.717). At the academic level variable, the odds of academic educated individuals with source separation behavior were 4.4 times higher than those with non-academic education $(\mathrm{OR}=4.447 ; 95 \% \mathrm{Cl}=1.554-12.727)$. The odds ratio of the subjects who understood the benefits of waste separation was 6.7 times more than those with a lower understanding of the benefits of source separation (OR = $6.746 ; 95 \% \mathrm{Cl}=2.534-17.959$ ). . People who understood the structural barriers at a lower level were 12.7 times more likely to perform source separation behavior than those who understand higher structural barriers $(\mathrm{OR}=12.734 ; 95 \% \mathrm{Cl}$ $=3.516-46.119$ ). 
Table 6. Results of logistic regression on the determinants of source separation behavior.

\begin{tabular}{|c|c|c|c|c|c|}
\hline \multirow{2}{*}{\multicolumn{2}{|c|}{ Variable }} & \multirow{3}{*}{$\begin{array}{l}\text { OR } \\
\text { REF }\end{array}$} & \multicolumn{2}{|c|}{ CI $95 \%$} & \multirow{3}{*}{$\begin{array}{r}\text { P. value } \\
0.025\end{array}$} \\
\hline & & & Lower & Upper & \\
\hline \multirow[t]{2}{*}{ Age } & $\begin{array}{l}\text { Less than } \\
30\end{array}$ & & & & \\
\hline & $\begin{array}{l}\text { Equal and } \\
\text { more than } \\
30\end{array}$ & 2.429 & 1.143 & 7.717 & \\
\hline Academic & $\begin{array}{l}\text { Non- } \\
\text { academic }\end{array}$ & REF & & & \multirow[t]{2}{*}{0.005} \\
\hline level & Academic & 4.447 & 1.554 & 12.727 & \\
\hline \multirow{2}{*}{ Benefits } & Down & REF & & & \multirow{2}{*}{0.001} \\
\hline & Up & 6.746 & 2.534 & 17.959 & \\
\hline \multirow{2}{*}{$\begin{array}{l}\text { Structural } \\
\text { barriers }\end{array}$} & Down & REF & & & \multirow{2}{*}{0.001} \\
\hline & Up & 12.734 & 3.516 & 46.119 & \\
\hline \multirow{2}{*}{ Motivation } & Down & REF & & & \multirow{2}{*}{0.001} \\
\hline & Up & 9.613 & 3.356 & 27.536 & \\
\hline \multirow{2}{*}{ Awareness } & Down & REF & & & \multirow{2}{*}{0.012} \\
\hline & Up & 3.917 & 1.351 & 11.356 & \\
\hline \multirow{2}{*}{$\begin{array}{l}\text { Social } \\
\text { norms }\end{array}$} & Down & REF & & & \multirow{2}{*}{0.044} \\
\hline & Up & 2.905 & 1.030 & 8.191 & \\
\hline
\end{tabular}

As to the motivation variable, those with higher motivation had 9.6 times higher odds of separating waste, compared with those with lower motivation $(\mathrm{OR}=9.613$; $95 \%$ $\mathrm{Cl}=3.356-27.536)$. The odds ratio of participants who had a higher awareness of waste disposal was 3.9 times higher than those with a lower awareness of the waste separation behavior (OR $=3.917 ; 95 \% \mathrm{Cl}=3.351-11.356)$. For the social norms, individuals with high social norms were 2.9 times more likely to perform separation behavior than those with low social norms $(\mathrm{OR}=2.905 ; 95 \% \mathrm{Cl}=1.030-8.191)$.

\section{Discussion}

One way to reduce the amount of waste at landfill and increase the recycling is source separation which is a key part of scientific waste management process; in other words, proper sorting and separating the wastes results in better refinement and disposal [12-14]. This study was conducted to determine the source separation behavior of waste and its determinants. The results showed that the rate of regular source separation among the female participants was $17.7 \%$, which is consistent with the results of the studies conducted in Iran in other cities. In the study carried out by Torkashvand et al., the rate of separated waste was $13.46 \%$ [44]. The results of the study by Hatami et al. also showed that $15 \%$ of the wastes in Tehran was collected separately [45]. In a study in South Africa, the source separation rate of the wastes was $3.3 \%$, [46] and in a study in Indonesia it was reported to be $18.4 \%$ [4]. In addition, a small percentage of individuals performed the separation and recycling behavior of the wastes in those countries, while the rate was much higher in developed countries [11]. In a study in Canada, about $92 \%$ of the participants stated that they performed waste separation and recycling [47]. In Germany, more than $90 \%$ of people voluntarily participate in the source separation program of source separation [19]. These results indicated that the participation of people, which is the most important part in source separation, was very limited in Iran.

One of the results of this study was the relationship between age and performing the source separation behavior of wastes. It was found that the probability of source separation behavior of waste increased with the women's age. In line with our results, various studies have shown that the rate of source separation and recycling behavior of waste increases with aging $[22,23,44,47,48]$. Therefore, it is necessary to design and perform promotional interventions in the field of source separation behavior of wastes by women at younger ages.

Regarding the level of education, the results showed that the chances of performing source separation behavior of wastes by the women holding a university degree were higher than those with non-university education. University education seems to increase the level of awareness and knowledge of the people about the environment and its future; in other words, it can be implied that they become more aware of the potential risks that might happen when no attention is paid to environmental and natural issues; thus, they become more responsible to waste separation. Similar to our results, several studies have shown a relationship between the level of education and the separation and recycling behavior of the wastes $[49,50]$. However, in the study by Kaciak and Kushner no relationship was observed between education and waste separation [47]. As to education, it is necessary to design and execute promotional interventions in the field of source separation behavior of wastes among women with no university education.

The results showed that the women who better understood the benefits of waste separation and imagined more positive outcomes for that were more likely to perform source separation behavior of waste. In a research by Kaciak, and Kushner and also by Mongkolnchaiarunya, Suttibak and Nitivattananon, the economic and financial benefits, and money-saving were effective on separation behavior of the wastes $[47,51,52]$. In a study conducted by Santoso, people's perception of the benefits of separation of wastes against the consequences of it resulted in a better performance of source separation behavior of wastes [4]. In other works, environmental benefits (i.e. reduced amount of waste) and human-centered benefits (i.e. helping cleanliness and future generations) were among the benefits of separation behavior of wastes [36,47]. The research findings on the importance of benefits suggest that interventions should be programed and performed to enhance the women's perception of the benefits of source separation.

One of the findings of this study was that the women who understood the structural barriers at a lower level had a higher chance of performing source separation behavior of wastes. In a study by Dale et al., which was conducted 
based on a community-based social marketing approach, it was reported that those who were faced with barriers such as commitment (space and time for separation and procedural unfamiliarity) and difficulty (distance, design, and access to bin) had less source separation behavior of wastes [36]. In a study by Cole and Fieselman, which was also conducted based on community-based social marketing approach, the results showed that paper separation was not widely accepted due to various barriers such as confidentiality, difficulty in using the other side of papers, etc. [28].

The results concerning the motivational construct showed that the higher the motivation of individuals for the separation of waste, the higher their chances of source separation behavior of wastes. Haghighatjoo et al. and Haldeman et al. who used the CBSM to promote recycling behavior also show that motivation is one of the main factors in performing recycling behavior. This is in line with the findings of our study $[53,54]$. Also consistent with our findings, Heidari, et al. showed that perceived benefit as a motivational factor was one of the predictors of waste management behavior [55]. Also, Kaciak and Kushner showed that individuals needed encouragement in the form of coupon or rewards and incentives such as protecting the land and environment and its resources, reducing air pollution and disease, and adhering to the norms and laws to perform separating and recycling of wastes. In their view, individuals should fathom out that participation in the separation of waste is not difficult and separating and recycling is a social norm [47]. Some researchers have also focused on intrinsic stimuli such as personal goals and beliefs, and shown a positive relationship between these variables and environmental behavior (separation and recycling) was observed $[56,57]$. In a review study by Miafodzyeva and Brandt, the results showed that environmental concerns were a major incentive for separating and recycling of waste [24].

In the present study, with increasing awareness, the rate and chance of performing separation behavior of waste were higher. In a CBSM study, Martin examined tailgaters recycling behavior and found that applying community-based social marketing strategies would increase awareness and ultimately increase the recycling behavior [30]. Haghighatjoo in a study designed based on CBSM strategies shows that these strategies increase awareness and recycling behavior [53]. These findings confirm the results of our study. The findings of Strydom, which is in line with the results of the present work, showed that the increased awareness highly raises the chances of people for the recycling and separating [46]. In a study by Hansmann, et al., knowledge on recycling was also positively correlated with recycling behavior [58]. Other researches have also raised awareness into how separation of wastes has led to an increase in their source separation behavior $[15,24,59,60]$. In a qualitative study by Sinthumule et al., knowledge was also an important barrier to poor participation and source separation [25].
Furthermore, social norms were also a determinant of source separation behavior, and individuals with higher social norms had a higher chance of performing source separation behaviors. Social norms act as a framework for individual behavior in society, and regarding the global environmental concerns and their effect on social norms or the emergence of new norms, it seems that observing these norms requires environmentally friendly behaviors such as separation of waste. Haghighatjoo et al. conducted a CBSM study to increase the recycling behavior among the students. In this study, recycling educators selected from among the students themselves were used as a social norm to promote the recycling behavior. The results of their study showed that social norm as a major factor in performing recycling behavior was effective. This is in line with the findings of our study [53]. Also consistent with our findings, Ghani et al. showed that source separation of food was influenced by the norms among individuals [61]; in other studies, the role of social and community norms, including family, neighbors, and important groups, was critical in the tendency of individuals to separate and recycle the wastes $[46,62]$. However, contrary to our results, in a study by Ayob et al. abstract norms and reference groups such as friends did not correlate with Malaysian students' tendency for source separation [15]. In some other studies, there was no relationship between pressure and social norms with source separation behavior of the wastes $[4,63,64]$. The reason for this difference is that in these studies, attitudes toward the separation and recycling are pre-established among individuals and they are not affected by external pressures and norms; however, the participants of the present study were influenced by norms.

As to the limitations of this study, our data were obtained based on a self-report questionnaire, which leads to probable bias in the results. Also, data of this study were collected from a sample of women in Genaveh Township. Therefore, the results of this study cannot be generalized to all groups of women in Iran. Further studies on other groups of women in other geographical areas of Iran are suggested.

\section{Practical Recommendations}

In conclusion, it can be argued that waste management and waste separation at source is impossible without considering the people as the main producers of waste. Given that an essential part of barriers to separation at source is internal, continuous communication with people and training and informativeness and promotion of literacy and knowledge of people about the importance and necessity of separation at source, the importance of waste separation at source in health and prevention of diseases and environmental pollution, and teaching the separation of various types of waste in different ways, such as using new and academic methods and using new communication platforms and potentials such as cyberspace, in addition to the visual media by producing 
short and documentary films or to address the issue of separation at source directly or indirectly in the form of films and television series can be useful. Creating campaigns by choosing attractive slogans and messages, motivating people to participate in separation activities can promote commitment in individuals and persuade them to participate in the behavior of separation at source.

In the external dimension of barriers, strengthening the infrastructure related to separation behavior such as providing separation arrangements and equipment such as the existence of a specific place for collection (recycling tanks and booths) and, their availability, installation of special waste bins for recycled materials in front of each house or alley, delivery of plastic bags with signs related to the type of separable waste, regular and systematic collection of separated waste and, providing modern machinery and equipment and strengthening the relevant industries, providing an information and electronic bank of the citizens participating in waste behavior and providing incentive packages such as paying for the delivery of separated materials at the end of each month to encourage people to continue separation behavior are important to remove barriers to citizen participation to a large extent.

Another useful and fundamental action is the development of social norms related to the behavior of separation at source to encourage people to do this behavior. Normalizing separation behavior by educating growing age groups such as children and adolescents during socialization and special use of school educational status will be very useful. Culturalization in the field of separation at source behavior and turning it into an essential part of people's actions can be achieved by deepening and institutionalizing the sense of belonging and responsibility of citizenship by entrusting part of the project to the people and involving them in urban participation. This recent action can lead to the spontaneous and continuous participation of citizens in which, they will voluntarily want to continue the behavior of separation at source and their actions will be guided and channeled by the officials. Holding weekly and monthly seminars and workshops at the neighborhood level and preparing brochures, catalogs and educational booklets on the importance of separation behavior and related training are also appropriate measures.

The final result of these practical processes will be to increase citizen participation by reducing barriers, reducing waste cycle costs, reducing waste-induced environmental pollution, and ultimately, sustainable urban development.

\section{References and Notes}

[1] Giddens A. The Consequences of Modernity. John Wiley \& Sons; 2013.

[2] Rhyner CR, Schwartz LJ, Wenger RB, Kohrell MG. Waste Management and Resource Recovery. CRC Press; 2017

[3] Dehghani M, Dehghanifard E, Kamal A, Asgari A, Baneshi M. A

\section{Conclusion}

One of the major environmental problems throughout the world, especially in developing communities, is the high production of waste. Alleviating this problem and managing it are not feasible without participation of citizens. The results of this study indicated the low participation rate in source waste separation. Increasing the rate of source separation and attracting people's participation require proper policymaking and creating basic educational and cultural programs and establishing the necessary infrastructure to encourage individuals to actively participate in the separation.

According to the results of the research, the source separation behavior is influenced by a set of factors, including separation benefits, barriers to the separation, motivation, awareness, and social norms. In this regard, the role of education and awareness of the phenomenon of separation of wastes and the way it is done is of high importance; also, interventions and awareness campaigns are crucial in increasing the awareness and empowering the individuals in this field. Accordingly, appropriate and practical trainings should be provided in these areas. Furthermore, policymaking should aim at enhancing public awareness as to the benefits of separation of the wastes both individually and socially, removing barriers and deterrents, and considering certain incentives.

Also, since women are the individuals who play a key role in housekeeping, policies should aim at increasing the awareness of all people, especially women, about the benefits of waste segregation, both individually and socially, and barriers and deterrents should be considered. There should be certain incentives. On the other hand, because the role of women in raising children is not usually hidden from anyone, with proper planning to encourage them to separate the wastes at home and educate them to do so, the next generation can be educated in a way that they support the environment and waste separation behavior is stablished in them. In this way, not only the short-term benefits will be advantageous for the community, but also the long-term environmental consequences will be beneficial.

\section{Acknowledgements}

The authors of the article would like to thank all the study participants. This study is part of a research dissertation approved by Iran University of Medical Sciences. The research was supported by grant No 97-3-2-13096 from Iran University of Medical Sciences.

Quantitative and Qualitative Investigation of Tehran Solid Waste Re cycling Potential. Knowledge Health. 2009;4(1):40-44. Available from: https://www.sid.ir/en/journal/ViewPaper.aspx?id=160099.

[4] Santoso AN. Community Participation in Household Waste Management: An Exploratory Study in Indonesia. In: E3S Web of Conferences. vol. 125. EDP Sciences; pp. 07013. $10.1051 /$ e3sconf/201912507013. 
[5] Guerrero-Abarca L, Maas G, Hogland W. Solid Waste Management Challenges for Cities in Developing Countries. Waste Management. 2013;33(1):220-232. doi:10.1016/j.wasman.2012.09.008.

[6] Ali A, Gumbe L, Mohammed A, Nathan N. Nairobi Solid Waste Management Practices: Need for Improved Public Participation and Involvement. Tanzania Journal of Forestry and Nature Conservation. 2010;80(1):61-73. Available from: https://www.ajol.info/index.php/ tjfnc/article/view/89352.

[7] Xiao Y, Bai X, Ouyang Z, Zheng H, Xing F. The Composition, Trend and Impact of Urban Solid Waste in Beijing. Environmental Monitoring and Assessment. 2007;135(1-3):21-30. doi:10.1007/s10661-0079708-0.

[8] Khajuria A, Yamamoto Y, Morioka T. Estimation of Municipal Solid Waste Generation and Landfill Area in Asian Developing Countries. Journal of Environmental Biology. 2010;31(5):649-654.

[9] Palmer JA. Environmental Education in the $21^{\text {st }}$ Century: Theory, Practice, Progress and Promise. Routledge; 2002.

[10] Shamshiry E, Nadi B, Mahmud AR. Proceedings of the International Conference on Biology, Environment and Chemistry. vol. 1;. pp. 119-121.

[11] Nazari A, Farzadkia M, Rastgar A, Ahmadi E. The 20 years View Study of Dry Waste Recycling in Qom and it's Economic Benefits. Journal of Sabzevar University Of Medical Sciences. 2014;20(4):530538.

[12] Jokela JP, Kettunen RH, Rintala JA. Methane and Leachate Pollutant Emission Potential from Various Fractions of Municipal Solid Waste (MSW): Effects of Source Separation and Aerobic Treatment. Waste Management \& Research. 2002;20(5):424-433. doi:10.1177/0734242X0202000506.

[13] Lederer J, Ongatai A, Odeda D, Rashid H, Otim S, Nabaasa M. The Generation of Stakeholder's Knowledge for Solid Waste Management Planning through Action Research: A Case Study from Busia, Uganda. Habitat International. 2015;50:99-109. doi:10.1016/j.habitatint.2015.08.015.

[14] Zhen-Shan L, Lei Y, Xiao-Yan Q, Yu-Mei S. Municipal Solid Waste Management in Beijing City. Waste Management. 2009;29(9):25962599. doi:10.1016/j.wasman.2009.03.018.

[15] Ayob SF, Sheau-Ting L, Abdul Jalil R, Chin HC. Key Determinants of Waste Separation Intention: Empirical Application of TPB. Facilities. 2017;35(11/12):696-708. doi:10.1108/F-06-2016-0065.

[16] Fahiminia M, Farzadkia M, Nazari S, Arsang Jang S, Soudabeh Matboo A, Ibrahimi A, et al. Evaluation of the Status of Citizen Participation in Municipal Waste Source Separation Plan and Offering Corrective Strategies. Qom University of Medical Sciences Journal. 2013;7(5):66-72. Available from: http://journal.muq.ac.ir/article-133-en.html.

[17] Rafei H, Shahnooshi N, Rahnama MR. Study and Ranking of Urban Regions Based on Citizens' Participation in Origin Separation of Waste by Using Several Criterion Programming (Case Study: Mashhad). Geographical Researches Quarterly Journal. 2013;28(2):195214. Available from: http://georesearch.ir/article-1-485-en.html.

[18] Farzadkia M, Moradi A, Mohammadi MS, Jorfi S. Hospital Waste Management Status in Iran: A Case Study in the Teaching Hospitals of Iran University of Medical Sciences. Waste Management \& Research. 2009:27(4):384-389. doi:10.1177/0734242X09335703.

[19] Schwarz-Herion O, Omran A, Rapp HP. A Case Study on Successful Municipal Solid Waste Management in Industrialized Countries by the Example of Karlsruhe City, Germany. Journal of Engineering Annals. 2008;6(3):266-273. Available from: http://annals.fih.upt.ro/pdffull/2008/ANNALS-2008-3-46.pdf.

[20] Persson A. Characterizing the Policy Instrument Mixes for Municipal Waste in Sweden and England. European Environment. 2006;16(4):213-231. doi:10.1002/eet.419.

[21] Metin E, Eröztürk A, Neyim C. Solid Waste Management Practices and Review of Recovery and Recycling Operations in Turkey. Waste Management. 2003;23(5):425-432. doi:10.1016/S0956053X(03)00070-9.

[22] Bortoleto AP, Kurisu KH, Hanaki K. Model Development for Household Waste Prevention Behaviour. Waste Management. 2012;32(12):2195-2207. doi:10.1016/j.wasman.2012.05.037.

[23] Lee S, Paik HS. Korean Household Waste Management and Recycling Behavior. Building and Environment. 2011;46(5):1159-1166. doi:10.1016/j.buildenv.2010.12.005.

[24] Miafodzyeva S, Brandt N. Recycling Behaviour among Householders: Synthesizing Determinants via a Meta-analysis. Waste and Biomass Valorization. 2013;4(2):221-235. doi:10.1007/s12649-012-9144-4.

[25] Sinthumule NI, Mkumbuzi SH. Participation in Community-based Solid Waste Management in Nkulumane suburb, Bulawayo, Zimbabwe. Resources. 2019;8(1):30. doi:10.3390/resources8010030.

[26] McKenzie-Mohr D. Fostering Sustainable Behavior: An Introduction to Community-based Social Marketing. New Society Publishers; 2011.

[27] Armijo-de Vega C, Ojeda-Benítez S, Aguilar-Virgen Q, TaboadaGonzález PA. Solid Waste Management in a Mexican University Using a Community-based Social Marketing Approach. The Open Waste Management Journal. 2010;3:146-154. doi:10.2174/1875934301003010146.

[28] Cole EJ, Fieselman L. A Community-based Social Marketing Campaign at Pacific University Oregon: Recycling, Paper Reduction, and Environmentally Preferable Purchasing. International Journal of Sustainability in Higher Education. 2013;14(2):176-195. Available from: https://eric.ed.gov/?id=EJ1004024.

[29] Township of Langley Backyard Composting Community-Based Social Marketing Study. Available from: http://www.beyondattitude.com/wpcontent/uploads/2011/06/LangleyBYC_CBSM_FinalReport.pdf.

[30] Martin NT, Ross SR, Irwin RL. Utilizing Community-based Social Marketing in a Recycling Intervention with Tailgaters. Journal of Intercollegiate Sport. 2015;8(1):57-81. doi:10.1123/jis.2014-0128.

[31] Smith B. Food Waste and Behavior Change on Campus. Pacific Lutheran University. 2015;pp. 1-12. Available from: https://www.plu.edu/sustainability/wp-content/uploads/sites/ 142/2016/05/food-waste-and-behavior-change-on-campus.pdf.

[32] Sun S, Gaal CV. Community Based Social Marketing Organics Diversion Pilot Program [Project Report]. Edmonton, Canada: University of Alberta, Faculty of Arts, Department of Interdisciplinary Studies; 2017. Available from: https://agenda.sprucegrove.org/docs/2017/COW/20170918_430/ 3079_Sustainability\%20Scholars\%20Project\%20Final\% 20Report_City\%20of\%20Spruce\%20Grove_Sky\%20Sun.pdf.

[33] Pocock R, Stone I, Clive H, Smith R, Jesson J, Wilczak S. Barriers to Recycling at Home. Banbury, UK: Waste and Resources Action Programme; 2008. Available from: https://wrap.org.uk/resources/ report/barriers-recycling-home.

[34] Recycle Lincoln. Available from: https://documents.pub/reader/full/ residential-recycling-barriers-benefits-report-residential-recyclingbarriers.

[35] Conde HM, Wright NG, Mohr SA. The Barriers Impeding Recycling Participation in the Borough of Croydon [PhD Thesis]. Worcester, MA, USA; 2007. Available from: https://web.wpi.edu/Pubs/E-project/ Available/E-project-042507-053608/unrestricted/D07Croydon.pdf.

[36] Dale E, Nobe MC, Clevenger C, Cross J. Community-based Social Marketing: An Application to Facilities Management. In: ICSDEC 2012: Developing the Frontier of Sustainable Design, Engineering, and Construction; 2013. pp. 552-560. doi:10.1061/9780784412688.066.

[37] Jesson JK, Stone I. A Review of Barriers to Kerbside Recycling Household Waste in the UK [Research Paper]. Birmingham, UK: Aston Business School; 2009. Available from: https://research.aston. ac.uk/files/229610/AWP__lit_review_recycling_09__pdf_.pdf.

[38] Mutang JA, Ismail R, Seok CB, Bahari F, Madlan L, Wider W, et al. Recycling Motivations and Barriers in Kota Kinabalu, Malaysia. International Journal of Psychological and Behavioral Sciences. 2015;9(8):2911-2915. doi:10.5281/zenodo.1109505.

[39] Omran A, Sarsour AK, Pakir AHK. An Investigation Into The Factors Influencing The Participation Of Households In Recycling Of Solid Waste. The International Journal of Health Economics. 2012;2(1):419. Available from: https://ideas.repec.org/a/but/ijhefa/v2y2012i1p419.html.

[40] Thomson I, Brain R. A Primer in Community-based Social Marketing Logan, UT, USA: Utah State University Extension; 2016. Available from: https://digitalcommons.usu.edu/extension_curall/1639.

[41] Tappen RM. Advanced Nursing Research: From Theory to Practice. Jones \& Bartlett Publishers; 2016.

[42] Lawshe CH. A Quantitative Approach to Content Validity. Per- 
sonnel Psychology. 1975;28(4):563-575. doi:10.1111/j.17446570.1975.tb01393.x.

[43] Vakili MM, Hidarnia AR, Niknami S. Development and Psychometrics of an Interpersonal Communication Skills Scale (ASMA) among Zanjan Health Volunteers. Journal of Hayat. 2012;18(1):5-19.

[44] Torkashvand J, Emamjomeh MM, Farzadkia M, Mahmodkhani R. Investigating the Source Separation Rate of Municipal Solid Waste and Economical and Social Determinance in Iran (2017). The Journal of Qazvin University of Medical Sciences. 2018;22(5):70-79. doi:10.29252/qums.22.5.70.

[45] Hatami A, Memarian Fard M, Sabour M. Evaluation of Waste Source Separation in 22 Districts of Tehran Using GIS. Journal of Geomatics Science and Technology. 2017;6(3):63-74. Available from: https://www.sid.ir/en/journal/ViewPaper.aspx?id=538634.

[46] Strydom W. Applying the Theory of Planned Behavior to Recycling Behavior in South Africa. Recycling. 2018;3(3):43. doi:10.3390/recycling3030043.

[47] Kaciak E, Kushner J. Determinants of Residents Recycling Behaviour. International Business \& Economics Research Journal (IBER). 2009;8(8). doi:10.19030/iber.v8i8.3154.

[48] Martin M, Williams ID, Clark M. Social, Cultural and Structural Influences on Household Waste Recycling: A Case Study. Resources, Conservation and Recycling. 2006;48(4):357-395. doi:10.1016/j.resconrec.2005.09.005.

[49] De Feo G, De Gisi S. Public Opinion and Awareness towards MSW and Separate Collection Programmes: A Sociological Procedure for Selecting Areas and Citizens with a Low Level of Knowledge. Waste Management. 2010;30(6):958-976. doi:10.1016/j.wasman.2010.02.019.

[50] Jenkins RR, Martinez SA, Palmer K, Podolsky MJ. The Determinants of Household Recycling: A Material-specific Analysis of Recycling Program Features and Unit Pricing. Journal of Environmental Economics and Management. 2003;45(2):294-318. doi:10.1016/S00950696(02)00054-2.

[51] Mongkolnchaiarunya J. Promoting a Community-based Solid-waste Management Initiative in Local Government: Yala Municipality, Thailand. Habitat International. 2005;29(1):27-40. doi:10.1016/S01973975(03)00060-2.

[52] Suttibak S, Nitivattananon V. Assessment of Factors Influencing the Performance of Solid Waste Recycling Programs. Resources, Conservation and Recycling. 2008;53(1-2):45-56. doi:10.1016/j.resconrec.2008.09.004.

[53] Haghighatjoo S, Tahmasebi R, Noroozi A. Application of CommunityBased Social Marketing (CBSM) to Increase Recycling Behavior (RB) in Primary Schools. Social Marketing Quarterly. 2020;26(4):297-308. doi:10.1177/1524500420962789.

[54] Haldeman T, Turner JW. Implementing a Community-based Social
Marketing Program to Increase Recycling. Social Marketing Quarterly. 2009;15(3):114-127. doi:10.1080/15245000903154618.

[55] Heidari A, Kolahi M, Behravesh N, Ghorbanyon M, Ehsanmansh F, Hashemolhosini N, et al. Youth and Sustainable Waste Management: A SEM Approach and Extended Theory of Planned Behavior. Journal of Material Cycles and Waste Management. 2018;20(4):2041-2053. doi:10.1007/s10163-018-0754-1.

[56] Cleveland M, Kalamas M, Laroche M. Shades of Green: Linking Environmental Locus of Control and Pro-environmental Behaviors. Journal of Consumer Marketing. 2005;22(4):198-212. doi:10.1108/07363760510605317.

[57] Corral-Verdugo V. Situational and Personal Determinants of Waste Control Practices in Northern Mexico: A Study of Reuse and Recycling Behaviors. Resources, Conservation and Recycling 2003;39(3):265-281. doi:10.1016/S0921-3449(03)00032-6.

[58] Hansmann R, Bernasconi P, Smieszek T, Loukopoulos $P$ Scholz RW. Justifications and Self-organization as Determinants of Recycling Behavior: The Case of Used Batteries. Resources, Conservation and Recycling. 2006;47(2):133-159. doi:10.1016/j.resconrec.2005.10.006.

[59] Hashim K, Abdul H, Mohamed S, Haneesa Z. Developing Conceptual Waste Minimization Awareness Model through Community based Movement: A Case Study of Green Team, International Islamic University Malaysia. In: Persidangan Kebangsaan Masyarakat, Ruangdan Alam Sekitar (MATRA 2011). Pulau Pinang, Malaysia; 2011. Available from: https://core.ac.uk/reader/300388660.

[60] Tonglet M, Phillips PS, Bates MP. Determining the Drivers for Householder Pro-environmental Behaviour: Waste Minimisation Compared to Recycling. Resources, Conservation and Recycling. 2004;42(1):27-48. doi:10.1016/j.resconrec.2004.02.001.

[61] Ghani WAWAK, Rusli IF, Biak DRA, Idris A. An Application of the Theory of Planned Behaviour to Study the Influencing Factors of Participation in Source Separation of Food Waste. Waste Management. 2013;33(5):1276-1281. doi:10.1016/j.wasman.2012.09.019.

[62] Do Valle PO, Reis E, Menezes J, Rebelo E. Behavioral Determinants of Household Recycling Participation: The Portuguese Case. Environment and Behavior. 2004;36(4):505-540. doi:10.1177/0013916503260892.

[63] Bamberg S, Rees J, Seebauer S. Collective Climate Action: Determinants of Participation Intention in Community-based Proenvironmental Initiatives. Journal of Environmental Psychology 2015;43:155-165. doi:10.1016/j.jenvp.2015.06.006.

[64] Barr S, Gilg AW. Conceptualising and Analysing Household Attitudes and Actions to a Growing Environmental Problem: Development and Application of a Framework to Guide Local Waste Policy. Applied Geography. 2005;25(3):226-247. doi:10.1016/j.apgeog.2005.03.007. 